\title{
What is the diagnostic accuracy of single nerve conduction studies and muscle ultrasound to identify critical illness polyneuromyopathy: a prospective cohort study
}

Daniel A. Kelmenson ${ }^{1 *}$ (D) Dianna Quan² and Marc Moss ${ }^{1}$

\begin{abstract}
Background: Critical illness polyneuromyopathy (CIPNM) is a major cause of weakness in intensive care unit (ICU) patients, but current diagnostic tests are limited. We evaluated the generalizability and validity of single nerve conduction studies (NCS) and muscle ultrasound testing to identify CIPNM, and we also assessed the ability of muscle ultrasound to prognosticate patient outcomes.

Methods: This was a prospective cohort study of mechanically ventilated medical, cardiac, surgical, and neurosurgical ICU patients. We performed weekly strength testing, NCS, electromyography (EMG), and muscle ultrasound. We calculated the sensitivity, specificity, and other test characteristics of single NCS and muscle ultrasound, and we used multivariable regression models to assess the prognostic ability of muscle ultrasound.

Results: Ninety-five patients were enrolled. The incidence of probable CIPNM was 18\% and did not differ significantly by type of ICU $(p=0.49$ ). For diagnosing probable CIPNM, the peroneal motor NCS had a sensitivity of 94\% (95\% confidence interval (Cl) 71-100\%) and specificity of 91\% (95\% Cl 82-96\%), the sural sensory NCS had a sensitivity of 100\% (95\% Cl 80-100\%) and specificity of 42\% (95\% Cl 31-54\%), and abnormal muscle ultrasound echogenicity had a sensitivity of $82 \%$ (95\% Cl 48-98\%) and specificity of 57\% (95\% Cl 43-70\%). Abnormal echogenicity was associated with reduced likelihood of discharge to home ( $9 \%$ vs 50\%, $p=0.0001$ ), fewer ICU-free days (median 3 (interquartile range $0-15)$ days vs 16 (9.3-19.3) days, $p=0.0002$ ), and increased ICU mortality ( $42 \%$ vs $12 \%, p=0.004)$.

Conclusions: In a diverse cohort of critically ill patients, single NCS and muscle ultrasound achieved diagnostic accuracy for patients at risk for CIPNM. The routine utilization of these tests could be beneficial for all critically ill patients at risk for CIPNM.
\end{abstract}

Keywords: Critical care, Critical care outcomes, Critical illness, Muscle weakness, Muscular diseases, Polyneuropathies

\footnotetext{
* Correspondence: Dkelmenson@gmail.com

${ }^{1}$ Division of Pulmonary Sciences \& Critical Care Medicine, University of Colorado School of Medicine, RM 9023, Mail Stop C272, 12700 East 19th Avenue, Aurora, CO 80045, USA

Full list of author information is available at the end of the article
}

(C) The Author(s). 2018 Open Access This article is distributed under the terms of the Creative Commons Attribution 4.0 International License (http://creativecommons.org/licenses/by/4.0/), which permits unrestricted use, distribution, and reproduction in any medium, provided you give appropriate credit to the original author(s) and the source, provide a link to the Creative Commons license, and indicate if changes were made. The Creative Commons Public Domain Dedication waiver (http://creativecommons.org/publicdomain/zero/1.0/) applies to the data made available in this article, unless otherwise stated. 


\section{Background}

Each year, approximately 1 million critically ill mechanically ventilated patients worldwide develop intensive care unitacquired weakness (ICUAW) [1]. The prevalence of ICUAW varies widely depending on factors such as the presence of sepsis and multi-organ failure [2-14]. Weakness may be related to deconditioning (weakness without electrophysiologic abnormalities) or critical illness polyneuromyopathy (CIPNM; weakness with electrophysiologic abnormalities) $[6,9,10,15,16]$. Differentiating deconditioning from CIPNM is clinically important, as these two groups of patients have different outcomes and distinct courses of recovery [17].

The diagnosis of CIPNM can be challenging. Muscle strength testing is difficult to perform in acutely ill patients and does not differentiate CIPNM from deconditioning [18]. Although nerve conduction studies (NCS) and needle electromyography (EMG) can delineate CIPNM from deconditioning, these tests are time-consuming, mildly invasive (for EMG), use expensive equipment, and require specialized training.

A number of simplified screening tests for CIPNM have been proposed. NCS of a single motor nerve (such as the peroneal, also known as fibular, nerve) or sensory nerve (such as the sural nerve) may be a relatively accurate screening test for CIPNM [11-13]. The advantages of single NCS include shorter testing duration (5-10 min vs 60-90 min for full NCS/EMG), noninvasiveness, and no need for volitional patient movement. Electrophysiologic abnormalities are associated with deleterious outcomes in critically ill patients, even in the absence of weakness $[17,19]$. However, a prior study examining the accuracy of single peroneal and sural NCS as screening tests for CIPNM focused almost exclusively on patients with severe sepsis [11]. Therefore, the generalizability of the accuracy of single NCS in screening for CIPNM is relatively unknown. Muscle ultrasound is also a promising technique to diagnose weakness by examining decreases in muscle thickness or changes in appearance (increased echogenicity) [20-34]. Muscle ultrasound has the potential advantage of being a relatively quick and noninvasive test that utilizes equipment present in most intensive care units (ICUs). However, the accuracy of ultrasound changes in muscle thickness or echogenicity to diagnose CIPNM remains unclear, and it is unknown if ultrasound provides prognostic information beyond that obtained from NCS/EMG.

The main purposes of our study were to determine the generalizability of unilateral peroneal and sural NCS for screening for CIPNM in a broader population, including critically ill cardiac, surgical, and neurosurgical patients, and to evaluate the accuracy of muscle ultrasound in screening for CIPNM and prognosticating outcomes in critically ill patients.

\section{Methods}

This was a prospective observational cohort study conducted at the University of Colorado Hospital, a tertiary academic institution. We enrolled patients from the medical, cardiac, surgical, and neurosurgical ICUs. The study was approved by the Colorado Multiple Institutional Review Board. All subjects or their proxies provided written informed consent prior to inclusion in the study. If a proxy was used for the initial consent, re-consent of the subject was attempted during the hospital course. Some of these data was previously presented as an abstract at the American Thoracic Society International Conference 2018.

We identified potentially eligible patients using daily screening for mechanically ventilated patients in the electronic health record of our hospital. For medical, cardiac, and surgical ICU patients, the study inclusion criteria were: 1 ) intubation for $>48 \mathrm{~h}$ with hypoxemia or hypercarbia in conjunction with severe sepsis or septic shock; or 2) ICU stay for $>48 \mathrm{~h}$ with multi-organ dysfunction and acute respiratory failure $\left(\mathrm{PaO}_{2} / \mathrm{FiO}_{2}<\right.$ 250) requiring mechanical ventilation. For neurosurgical ICU patients, the inclusion criterion was intubation for $>$ $48 \mathrm{~h}$ with nontraumatic subarachnoid or intracerebral hemorrhage. Exclusion criteria for all ICUs included age < 18 years, pre-existing neuropathy or myopathy, pharmacologic paralysis, pregnancy, being a prisoner, time on mechanical ventilation and ICU stay of $>7$ days, inability to perform NCS/EMG on at least one arm and one leg (e.g., due to amputation or overlying equipment), or patient/ physician refusal to participate in the study.

After enrollment, we collected baseline information on demographics, comorbidities, and Sequential Organ Failure Assessment (SOFA) score. Each week, patients underwent Glasgow Coma Scale (GCS) scoring, and muscle strength testing was attempted using Medical Research Council (MRC) scoring of six bilateral muscle groups with a maximum score of 60 . ICUAW was defined as an MRC score of less than 48 [6].

Weekly NCS/EMG testing was performed with a Natus Neurology Nicolet Viking EDX (Middleton, WI, USA) according to previously described standard procedures $[11,35]$. Repetitive stimulation of the median motor nerve was performed to exclude neuromuscular junction defects, and F-waves were recorded from the tibial nerves to screen for proximal nerve root disease (e.g., GuillainBarre Syndrome). The bilateral sural, radial, and median sensory NCS were recorded using standard procedures [11]. The bilateral peroneal, tibial, and median motor NCS were recorded using surface electrodes over the extensor digitorum brevis, abductor hallucis brevis, and abductor pollicis brevis muscles, respectively. The compound motor action potential (CMAP) responses were elicited from standard distal and proximal sites of stimulation to 
calculate a conduction velocity and to assess for the presence of conduction block or temporal dispersion. After reviewing the studies and excluding patients with defects in neuromuscular transmission or primary/acquired demyelination, the sensory nerve action potential (SNAP) and CMAP amplitudes were analyzed for abnormalities. Unilateral concentric needle EMG examination was then performed on two upper extremity and two lower extremity muscles, one proximal and one distal in each limb, assessing insertional activity, spontaneous activity, activation, motor unit potential morphology, and recruitment pattern. NCS and EMG are prone to differences in interexaminer reliability but maintain high intraexaminer reliability [36]. Therefore, all NCS/EMG examinations were performed by one electrophysiology-trained physician, who was not blinded to the results of the index tests or reference standard.

For muscle ultrasound, we used a Philips Sparq machine (Amsterdam, Netherlands) with a linear-array transducer with standardized gain and varying depth based on the amount of overlying soft tissue and muscle size. The patients were examined in the supine position with extended limbs and relaxed muscles. We performed bilateral scans at standardized sites on the mid-biceps (halfway between the tip of the acromion and antecubital skin crease with forearm supinated), anterior mid-forearm (halfway between the antecubital skin crease and ulnar styloid with forearm supinated), and mid-thigh (halfway between the anterior superior iliac spine and superior midline border of the patella). We measured muscle thickness and echogenicity in the axial plane (perpendicular to the underlying bone or interosseous membrane) while avoiding compression of overlying soft tissues. To quantify muscle echogenicity, we utilized the visual four-point Heckmatt score that correlates with clinical and histologic neuromyopathy $[29,33]$. All muscle ultrasounds were performed before NCS/EMG by one trained examiner to minimize issues of interexaminer reliability. Only medical, cardiac and surgical ICU patients underwent weekly muscle ultrasound due to machine availability. Weekly NCS/EMG/ultrasounds stopped once the patient left the ICU, died, developed CIPNM or completed four weekly examinations.

The primary outcomes for this study were the sensitivity and specificity of the unilateral peroneal motor and sural sensory nerves for diagnosing CIPNM, using the previously reported most accurate cutoff amplitudes to define test positivity for the peroneal and sural nerves (below $0.65 \mathrm{mV}$ for peroneal and $4 \mu \mathrm{V}$ for sural) and a reference standard electrophysiologic definition of CIPNM based on established criteria [11]. Patients were diagnosed with CIPNM if they had: 1) SNAP amplitudes less than $80 \%$ of the lower limit of normal in two or more nerves; and 2) CMAP amplitudes less than $80 \%$ of the lower limit of normal in two or more nerves without conduction block.
NCS were categorized as normal or abnormal using standard normal values for the electrophysiology laboratory (normal amplitude $>1 \mathrm{mV}$ for the peroneal nerve and $>10$ $\mu \mathrm{V}$ for the sural nerve). We used this purely electrophysiologic definition of CIPNM (hereafter referred to as probable CIPNM) as our reference standard as we anticipated that most patients would not be awake and able to participate in voluntary MRC and EMG testing [8]. If the patient could participate in testing, MRC and EMG were used to classify the diagnosis definitively as neuropathy, myopathy, both, or neither. For patients diagnosed with probable CIPNM, the electrophysiological testing results at the time the diagnostic criteria were fulfilled were used in all analyses. For the remaining patients who did not meet the diagnostic criteria for probable CIPNM, data from their last electrophysiological tests were used in all analyses. Muscle ultrasound does not have established cutoffs to define abnormal changes in muscle thickness or echogenicity that are associated with CIPNM. We thus evaluated whether decreased muscle ultrasound thickness or increased echogenicity were accurate screening tests for probable CIPNM and if these muscle ultrasound abnormalities added prognostic information on patient outcomes to that obtained from NCS/EMG. We built a multivariable regression model with selected predictors of age (continuous variable), gender (binary variable), SOFA score for disease severity (continuous), CIPNM status (probable CIPNM vs none, binary), and muscle ultrasound echogenicity (abnormal vs normal, binary). The main predicted outcome for assessing the incremental prognostic information conveyed by muscle ultrasound was hospital discharge disposition (home vs not home) using a nominal logistic regression model with coefficient statistical significance assessed using a Wald test. We also examined the outcomes of ICU-free days and ICU mortality in secondary analyses.

We followed the Standards for Reporting Diagnostic Accuracy (STARD) 2015 guidelines for reporting diagnostic accuracy studies [37]. For our sample size calculation, since prior studies showed $~ 95 \%$ sensitivity of the peroneal motor and sural sensory nerves for CIPNM diagnosis [11-13], for a test with $95 \%$ sensitivity, two-sided $95 \%$ confidence interval (CI) width of $10 \%$, and probable CIPNM prevalence of 20\%, 92 patients would be needed [38]. Although our focus for these screening tests was sensitivity, these same prior studies showed $\sim 75 \%$ specificity of the peroneal nerve for CIPNM diagnosis and for a test with $75 \%$ specificity, two-sided $95 \%$ CI width of $10 \%$, and probable CIPNM prevalence of 20\%, 91 patients would be needed [38]. Baseline data are presented as counts and percentage or medians and interquartile range (IQR). We used chi-square tests for categorical variables and $t$ tests or Wilcoxon tests for continuous variables. Outcomes are presented as percentages for binary outcomes and medians and IQR for continuous 
outcomes. All analyses were performed using JMP Pro 13 (Buckinghamshire, England). A $p$ value less than 0.05 was considered statistically significant and all significance tests were two-sided. There was no adjustment performed for multiple comparisons.

\section{Results}

From December 2015 to April 2018, 255 mechanically ventilated patients met inclusion criteria and 155 were excluded (Fig. 1), with the most common reasons including an inability to obtain informed consent or refusal to participate ( $n=98$, usually from lack of available proxy), pre-existing neuromyopathy $(n=29)$, and pharmacologic paralysis $(n=4)$. We initially enrolled 100 patients. After enrollment and initial NCS/EMG were performed, five subjects were discovered to have a history of pre-existing neuromyopathy so they were excluded from further analysis. Thus, the final cohort included 95 patients (Table 1). No patients withdrew from the study and outcomes were collected on all patients.
Patients were awake, following commands, and able to participate in MRC strength testing at only $35 \%$ of study visits. A total of 17 patients (18\%) were diagnosed with probable CIPNM, and only 1 of these 17 patients could participate in voluntary EMG and MRC testing before discharge to determine definitively if they had neuropathy, myopathy, or both. Of the 17 patients diagnosed with probable CIPNM, 15 were diagnosed at their first study visit (the other 2 were diagnosed at study day 14 and day 21, respectively). Patients who developed probable CIPNM had fewer 28-day ICU-free days (0 (IQR 0-1.5) vs $8(0-17), p=0.007)$, were less likely to be discharged home ( $6 \%$ vs $32 \%, p=0.03)$, and were more likely to die in the ICU $(47 \%$ vs $18 \%, p=0.01)$ or hospital $(53 \%$ vs $19 \%$, $p=0.004$ ) when compared with patients who did not develop CIPNM. There was no difference in days on mechanical ventilation (10 (IQR 6.5-14.5) vs 9 (6-17), $p=0.67)$. The incidence of probable CIPNM did not differ significantly by admitting ICU $(p=0.49)$, and there was a similar probable CIPNM incidence in the medical (18\%) and neurosurgical (21\%) ICUs.

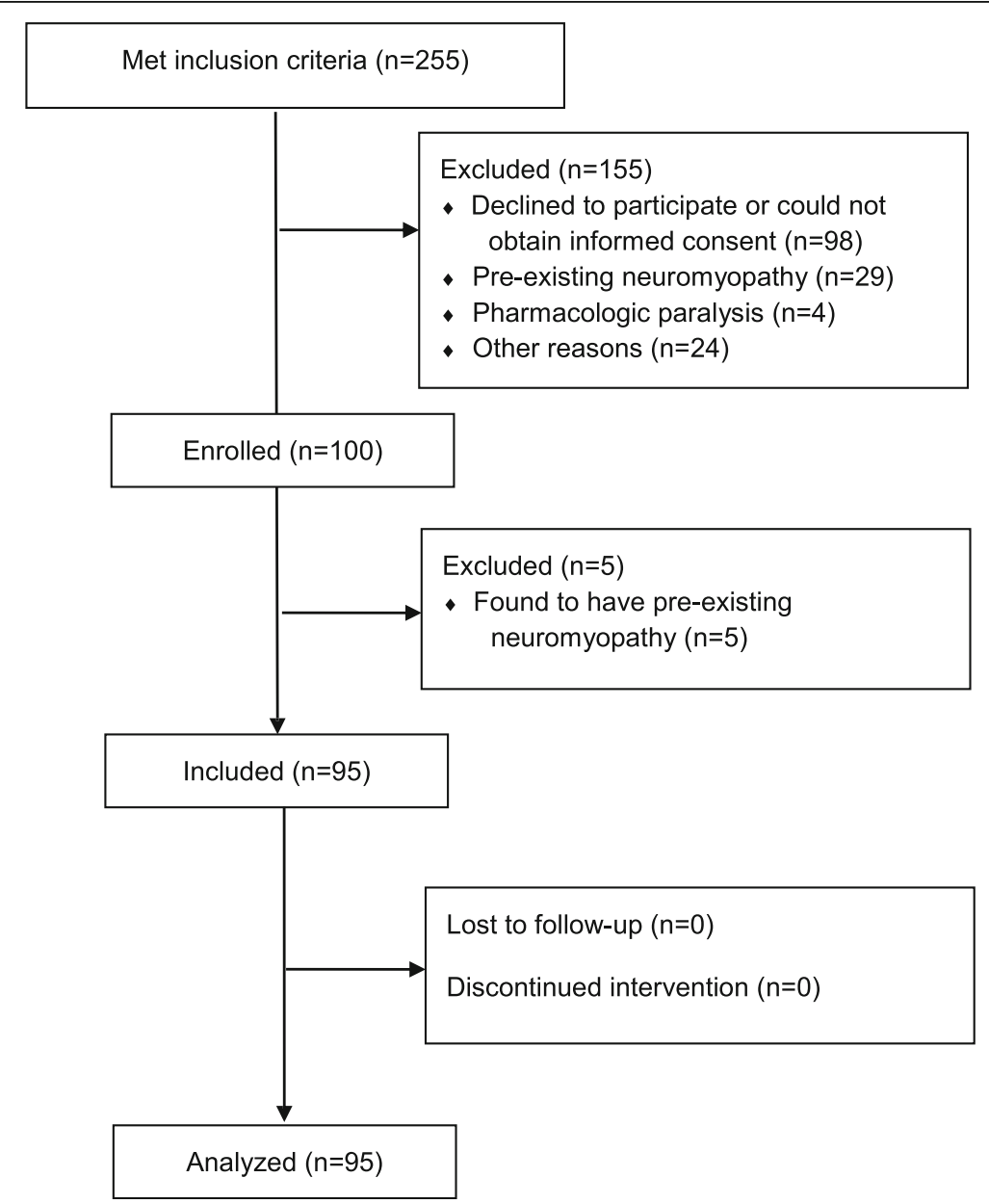

Fig. 1 Study flow chart 
Table 1 Baseline demographic and clinical characteristics

\begin{tabular}{|c|c|c|c|}
\hline Variables & Subjects $(n=95)$ & No CIPNM $(n=78)$ & Probable CIPNM $(n=17)$ \\
\hline \multicolumn{4}{|l|}{ ICU location } \\
\hline Medical & $45(47)$ & $37(47)$ & $8(47)$ \\
\hline Cardiac & $9(9)$ & $9(12)$ & $0(0)$ \\
\hline Surgical & $13(14)$ & $10(13)$ & $3(18)$ \\
\hline Neurosurgical & $28(29)$ & $22(28)$ & $6(35)$ \\
\hline Age, years & $59(43-70)$ & $56(43-65)$ & $72(59-77)$ \\
\hline Gender, female & $42(44)$ & $37(47)$ & $5(29)$ \\
\hline \multicolumn{4}{|l|}{ Race } \\
\hline White & $68(72)$ & $56(72)$ & $12(71)$ \\
\hline Black & $13(14)$ & $12(15)$ & $1(6)$ \\
\hline American Indian or Alaska Native & $3(3)$ & $2(3)$ & $1(6)$ \\
\hline Asian & $1(1)$ & $1(1)$ & $0(0)$ \\
\hline Other or not reported & $10(11)$ & $7(9)$ & $3(18)$ \\
\hline Ethnicity, Hispanic & $13(14)$ & $10(13)$ & $3(18)$ \\
\hline Body mass index, $\mathrm{kg} / \mathrm{m}^{2}$ & $28.7(25-32.3)$ & $28(24.6-31.9)$ & $29.4(27.7-37.9)$ \\
\hline \multicolumn{4}{|l|}{ Primary reason for admission } \\
\hline Subarachnoid hemorrhage & $19(20)$ & $14(18)$ & $5(29)$ \\
\hline Pneumonia & $17(18)$ & $15(19)$ & $2(12)$ \\
\hline Encephalopathy & $9(9)$ & $7(9)$ & $2(12)$ \\
\hline Intracerebral hemorrhage & $8(8)$ & $7(9)$ & $1(6)$ \\
\hline Postoperative & $7(7)$ & $7(9)$ & $0(0)$ \\
\hline Nonpulmonary sepsis & $7(7)$ & $4(5)$ & $3(18)$ \\
\hline Gastrointestinal bleed & $5(5)$ & $2(3)$ & $3(18)$ \\
\hline Congestive heart failure & $3(3)$ & $3(4)$ & $0(0)$ \\
\hline ARDS & $3(3)$ & $3(4)$ & $0(0)$ \\
\hline Myocardial infarction & $2(2)$ & $2(3)$ & $0(0)$ \\
\hline Other & $15(16)$ & $14(18)$ & $1(6)$ \\
\hline Hospital length of stay, hours & $108(66-157)$ & $108(66-152)$ & $116(76-162)$ \\
\hline Time on mechanical ventilation, hours & $83(63-133)$ & $83(63-134)$ & $84(69-135)$ \\
\hline Central nervous system disease & $11(12)$ & $8(10)$ & $3(18)$ \\
\hline Alcohol use disorder & $23(24)$ & $16(21)$ & $7(41)$ \\
\hline Diabetes & $12(13)$ & $10(13)$ & $2(12)$ \\
\hline HIV & $0(0)$ & $0(0)$ & $0(0)$ \\
\hline Total SOFA score & $9(6-12)$ & $9(6-11)$ & $12(8-14)$ \\
\hline Total GCS score (eyes + motor) & $4(2-9)$ & $7(2-9)$ & $2(2-7)$ \\
\hline
\end{tabular}

Data are presented as count (percentage) or median (interquartile range)

ARDS acute respiratory distress syndrome, CIPNM critical illness polyneuromyopathy, GCS Glasgow Coma Scale, HIV human immunodeficiency virus, ICU intensive care unit, SOFA Sequential Organ Failure Assessment

There were no statistical differences in the distribution of the right and left CMAP amplitudes for the peroneal nerve $(0 \mathrm{mV}$ (IQR -0.6 to 0.4$))$ and SNAP amplitudes for the sural nerve $(0 \mu \mathrm{V}(0-0))$, and so the right and left amplitude values were averaged when they were both obtained. Using the previously reported most accurate cutoff amplitudes for the peroneal and sural nerves (0.65 $\mathrm{mV}$ for peroneal and $4 \mu \mathrm{V}$ for sural) [11], the peroneal motor nerve had a sensitivity of $94 \%$ (95\% CI $71-100 \%)$ and specificity of $91 \%$ (95\% CI $82-96 \%)$ for diagnosing probable CIPNM compared with the reference standard, while the sural sensory nerve had a sensitivity of $100 \%$ (95\% CI $80-100 \%$ ) and specificity of $42 \%$ (95\% CI 31-54\%). The peroneal motor nerve had a positive predictive value of $70 \%$ and negative predictive value of $99 \%$, whereas the sural sensory nerve had a positive predictive 
value of $27 \%$ and negative predictive value of $100 \%$ (Table 2; Additional file 1: Figure S1 and Additional file 2: Figure S2). The sensitivities were unchanged when using cutoff amplitudes of $80 \%$ of the lower limit of normal for our laboratory (Table 3). The global accuracy of each test (the sum of true positives and true negatives divided by the total population) was $92 \%$ for the peroneal motor nerve and $53 \%$ for the sural sensory nerve.

The 67 patients in the medical, cardiac, and surgical ICUs who underwent muscle ultrasound had a median of one study performed per patient; 33 patients $(49 \%)$ had the worst echogenicity score in any muscle of 2 , and no muscles had scores of 3 or 4 . A muscle ultrasound echogenicity score in any muscle of at least 2 out of 4 had a sensitivity of $82 \%$ (95\% CI 48-98\%) and specificity of 57\% (95\% CI $43-$ 70\%) for diagnosing probable CIPNM compared with the reference standard, along with a positive predictive value of $27 \%$ and negative predictive value of $94 \%$ (Additional file 3 : Figure S3). The global accuracy of the test was $61 \%$. In all of the patients with probable CIPNM and abnormal echogenicity, the sural and peroneal single NCS were both abnormal. Increased echogenicity was associated with a reduced likelihood of discharge to home ( $9 \%$ vs $50 \%, p=$ $0.0001)$ and fewer ICU-free days (3 (IQR 0-15) vs 16 (9.3$19.3), p=0.0002)$ along with increased ICU mortality ( $42 \%$ vs $12 \%, p=0.004)$. We then determined if ultrasound added prognostic information to that obtained from NCS/EMG. For the main outcome of hospital discharge disposition, abnormal muscle ultrasound echogenicity was associated with a lower chance of discharge to home (odds ratio 0.42 (95\% CI 0.2-0.86), $p=0.02$ ) after adjustment for all the other predictors in the multivariable regression model. For the secondary outcomes, there were no significant associations between abnormal muscle ultrasound echogenicity and ICU-free days or ICU mortality. Only 13 patients had repeated studies of muscle thickness, so we could not examine changes in muscle thickness in this cohort.

The only adverse event was one thigh hematoma after EMG that did not expand after holding pressure and did not require further treatment intervention.

\section{Discussion}

In this prospective observational cohort study, we enrolled 95 heterogeneous critically ill intubated patients

Table 2 Results of index tests and reference standard

\begin{tabular}{llll}
\hline $\begin{array}{l}\text { Peroneal motor } \\
<0.65 \mathrm{mV}\end{array}$ & $\begin{array}{l}\text { Sural sensory } \\
<4 \mu \mathrm{V}\end{array}$ & No CIPNM & Probable CIPNM \\
\hline No & No & 32 & 0 \\
No & Yes & 39 & 1 \\
Yes & No & 1 & 0 \\
Yes & Yes & 6 & 16 \\
\hline
\end{tabular}

CIPNM critical illness polyneuromyopathy
Table 3 Sensitivity and specificity of each nerve amplitude for the diagnosis of probable CIPNM

\begin{tabular}{|c|c|c|c|c|}
\hline Nerve & $\begin{array}{l}\text { Cutoff } \\
\text { amplitude }\end{array}$ & $\begin{array}{l}\text { Normal } \\
\text { amplitude }\end{array}$ & $\begin{array}{l}\text { Sensitivity } \\
(95 \% \mathrm{Cl})\end{array}$ & $\begin{array}{l}\text { Specificity } \\
(95 \% \mathrm{Cl})\end{array}$ \\
\hline $\begin{array}{l}\text { Peroneal } \\
\text { motor }\end{array}$ & $0.65 \mathrm{mV}$ & $1 \mathrm{mV}$ & $94 \%(71-100 \%)$ & $91 \%(82-96 \%)$ \\
\hline $\begin{array}{l}\text { Peroneal } \\
\text { motor }\end{array}$ & $0.8 \mathrm{mV}$ & $1 \mathrm{mV}$ & $94 \%(71-100 \%)$ & $90 \%(81-95 \%)$ \\
\hline Sural sensory & $4 \mu \mathrm{V}$ & $10 \mu \mathrm{V}$ & $100 \%(80-100 \%)$ & $42 \%(31-54 \%)$ \\
\hline Sural sensory & $8 \mu \mathrm{V}$ & $10 \mu \mathrm{V}$ & $100 \%(80-100 \%)$ & $31 \%(21-42 \%)$ \\
\hline
\end{tabular}

$\mathrm{Cl}$ confidence interval, CIPNM critical illness polyneuromyopathy

and performed serial NCS, needle EMG, and muscle ultrasound to examine simplified screening tests for probable CIPNM. Individual peroneal CMAP and sural SNAP amplitudes had good sensitivity for identifying patients with probable CIPNM, and abnormal muscle echogenicity was a good screening test for probable CIPNM and a predictor of prognosis.

CIPNM is associated with a number of adverse patient outcomes, including prolonged time on mechanical ventilation, longer ICU and hospital stays, increased hospital mortality, higher hospital costs, and a lower likelihood of discharge to home $[6,7,10,11,15,16,39-42]$. Following hospital discharge, CIPNM is also associated with increased 1-year mortality [17, 41]. Furthermore, in survivors of acute respiratory distress syndrome (ARDS) examined 5 years after their initial illness, physical function was diminished whereas pulmonary function largely returned to normal [43].

Our group previously published a prospective observational cohort study of medical ICU patients with severe sepsis and/or acute respiratory failure requiring mechanical ventilation to determine which specific motor or sensory nerves accurately screened for CIPNM [11]. Using an amplitude cutoff value from receiver operating characteristic (ROC) curves of $0.65 \mathrm{mV}$ for the peroneal CMAP and $4 \mu \mathrm{V}$ for the sural SNAP, the unilateral peroneal motor nerve was $94 \%$ sensitive and $74 \%$ specific and the sural sensory nerve was $94 \%$ sensitive and $70 \%$ specific for diagnosing CIPNM. Latronico et al. also explored the use of unilateral peroneal motor NCS as a screening test for CIPNM in a diverse ICU population and validated the results in a primarily neurological ICU population. This group also found the peroneal nerve to have excellent sensitivity (100\%) for CIPNM diagnosis with good specificity $(67-85 \%)[12,13]$. Our study validates those prior results and demonstrates their generalizability to a broader critically ill patient population including patients with sepsis, neurologic emergency, and postoperative respiratory failure. As one of the longest nerves in the body, the utility of the peroneal nerve for diagnosing CIPNM may be partially explained by its vulnerability to tissue ischemia [13]. 
Critically ill patients experience both muscle wasting and a change in muscle appearance on ultrasound (increased echogenicity) [20-24]. Measurements of muscle ultrasound thickness and echogenicity have high inter-rater reliability in both healthy [25-27] and critically ill patients [28, 29]. Even in the presence of critical illness and edema, muscle thickness measurements at the biceps, mid-forearm, and mid-thigh correlate well with lean body mass [27, 30]. Muscle thickness decreases faster in critically ill patients with multi-organ failure [31]. Increased muscle echogenicity may be caused by intramuscular inflammation, necrosis, edema, fatty deposition, and/or fibrosis [29, 32, 33]. Our study demonstrates that increased echogenicity is a good screening test for probable CIPNM and is associated with deleterious outcomes.

Strengths of our study include generalizability through enrollment of a broad population of critically ill patients with a variety of diagnoses from multiple ICUs. We excluded patients with known pre-existing neuromyopathy through medical record searches and questioning of patients and proxies, supporting the validity of our findings. Single nerve screening tests for CIPNM should only be used in patients without pre-existing neuromuscular disease.

Our study has a number of limitations. The physician performing the electrophysiologic tests was unblinded, although muscle ultrasound was always performed before NCS/EMG at each weekly visit so that electrophysiologic testing results would not influence ultrasound interpretation. Since peroneal and sural NCS results were included as part of the reference standard criteria for probable CIPNM and both the index and reference tests were performed by the same specialist, the study was at risk of incorporation bias, which may lead to overestimation of diagnostic accuracy of our screening tests. We did not perform nerve or muscle biopsies, but it is impractical to perform these invasive procedures in most critically ill patients. It is possible that some of the changes in muscle echogenicity were due to edema, but fluid overload itself may still be harmful [44]. The prevalence of probable CIPNM in our study was $18 \%$, which was slightly lower than the $20 \%$ prevalence we expected in our sample size calculations and led to wider confidence intervals for index test sensitivity. We could not perform MRC strength testing due to altered mental status in the majority of study visits, consistent with prior literature demonstrating that most prolonged mechanically ventilated patients are unable to perform manual muscle testing [18]. The inability to perform manual muscle testing gives NCS and muscle ultrasound a potential advantage, as these tests require no active patient cooperation.

There are a number of implications of our study for clinical management. Compared with full four-limb NCS/EMG, unilateral single nerve NCS is quicker, less painful for the patient, and could facilitate the diagnosis of CIPNM. The peroneal CMAP amplitude is 100- to 1000-times larger than the sural SNAP amplitude and is thus easier to find in ICUs that frequently have electrical interference. However, an abnormal peroneal or sural NCS requires follow-up with full NCS/EMG (and ideally muscle strength testing) to confirm a CIPNM diagnosis. Abnormal muscle echogenicity is a good screening test for probable CIPNM and provides additional prognostic information to NCS/EMG. Simplifying the diagnosis of CIPNM with single nerve NCS or muscle ultrasound would have a dramatic impact on clinical practice, leading to earlier diagnosis and increased recognition of CIPNM, better prognostication for patients and families, and more targeted use of treatments such as physical therapy.

\section{Conclusions}

Peroneal motor and sural sensory single NCS are accurate diagnostic tests for probable CIPNM, and muscle ultrasound echogenicity adds value for outcome prediction. Future studies should examine whether these simplified tests can identify good candidates for early ICU physical therapy or be used to monitor therapeutic response.

\section{Additional files}

Additional file 1: Figure S1. STARD flow diagram for 95 patients undergoing sural NCS index test. (DOC $43 \mathrm{~kb}$ )

Additional file 2: Figure S2. STARD flow diagram for 95 patients undergoing peroneal NCS index test. (DOC 43 kb)

Additional file 3: Figure S3. STARD flow diagram for 67 patients undergoing muscle ultrasound echogenicity index test. (DOC 44 kb)

\section{Abbreviations \\ ARDS: Acute respiratory distress syndrome; Cl: Confidence interval; CIPNM: Critical illness polyneuromyopathy; CMAP: Compound motor action potential; EMG: Electromyography; GCS: Glasgow Coma Scale; ICU: Intensive care unit; ICUAW: Intensive care unit-acquired weakness; IQR: Interquartile range; MRC: Medical Research Council; NCS: Nerve conduction studies; ROC: Receiver operating characteristic; SNAP: Sensory nerve action potential; SOFA: Sequential Organ Failure Assessment}

\section{Acknowledgments}

Not applicable.

\section{Funding}

MM has received grant funding from the National Institutes of Health (K24 HL089223 and R01 NR011051). The National Institutes of Health had no role in the design of the study or collection, analysis, or interpretation of data, or in writing the manuscript.

\section{Availability of data and materials}

The datasets used and/or analyzed during the current study are available from the corresponding author on reasonable request.

\section{Authors' contributions}

MM originated the concept for this study. DAK collected, analyzed, and interpreted the patient data. DQ reviewed electrophysiologic data for accuracy. MM, DAK, and DQ were major contributors in writing the manuscript. All authors read and approved the final manuscript. 


\section{Ethics approval and consent to participate}

The study was approved by the Colorado Multiple Institutional Review Board. All subjects or their proxies provided written informed consent prior to inclusion in the study.

\section{Consent for publication}

Not applicable.

\section{Competing interests}

The authors declare that they have no competing interests.

\section{Publisher's Note}

Springer Nature remains neutral with regard to jurisdictional claims in published maps and institutional affiliations.

\section{Author details}

'Division of Pulmonary Sciences \& Critical Care Medicine, University of Colorado School of Medicine, RM 9023, Mail Stop C272, 12700 East 19th Avenue, Aurora, CO 80045, USA. ²Department of Neurology, University of Colorado School of Medicine, Aurora, CO, USA.

\section{Received: 8 October 2018 Accepted: 27 November 2018} Published online: 17 December 2018

\section{References}

1. Fan E, Cheek F, Chlan L, Gosselink R, Hart N, Herridge MS, et al. An official American Thoracic Society Clinical Practice guideline: the diagnosis of intensive care unit-acquired weakness in adults. Am J Respir Crit Care Med. 2014;190:1437-46.

2. Stevens RD, Marshall SA, Cornblath DR, Hoke A, Needham DM, de Jonghe B, et al. A framework for diagnosing and classifying intensive care unit-acquired weakness. Crit Care Med. 2009;37:5299-308.

3. de Jonghe B, Lacherade J-C, Sharshar T, Outin H. Intensive care unit-acquired weakness: risk factors and prevention. Crit Care Med. 2009;37:S309-15.

4. Schefold JC, Bierbrauer J, Weber-Carstens S. Intensive care unit-acquired weakness (ICUAW) and muscle wasting in critically ill patients with severe sepsis and septic shock. J Cachexia Sarcopenia Muscle. 2010;1:147-57.

5. Batt J, dos Santos CC, Cameron Jl, Herridge MS. Intensive care unit-acquired weakness: clinical phenotypes and molecular mechanisms. Am J Respir Crit Care Med. 2013;187:238-46.

6. De Jonghe B, Sharshar T, Lefaucheur J-P, Authier F-J, Durand-Zaleski I, Boussarsar $\mathrm{M}$, et al. Paresis acquired in the intensive care unit: a prospective multicenter study. JAMA. 2002;288:2859-67.

7. Ali NA, O'Brien JM, Hoffmann SP, Phillips G, Garland A, Finley JCW, et al. Acquired weakness, handgrip strength, and mortality in critically ill patients. Am J Respir Crit Care Med. 2008;178:261-8.

8. Latronico N, Bolton CF. Critical illness polyneuropathy and myopathy: a major cause of muscle weakness and paralysis. Lancet Neurol. 2011;10:931-41.

9. Bednarik J, Lukas Z, Vondracek P. Critical illness polyneuromyopathy: the electrophysiological components of a complex entity. Intensive Care Med. 2003;29:1505-14.

10. Khan J, Harrison TB, Rich MM, Moss M. Early development of critical illness myopathy and neuropathy in patients with severe sepsis. Neurology. 2006; 67:1421-5.

11. Moss M, Yang M, Macht M, Sottile P, Gray L, McNulty M, et al. Screening for critical illness polyneuromyopathy with single nerve conduction studies. Intensive Care Med. 2014;40:683-90.

12. Latronico N, Bertolini G, Guarneri B, Botteri M, Peli E, Andreoletti S, et al. Simplified electrophysiological evaluation of peripheral nerves in critically ill patients: the Italian multi-centre CRIMYNE study. Crit Care. 2007;11:R11.

13. Latronico N, Nattino G, Guarneri B, Fagoni N, Amantini A, Bertolini G, et al. Validation of the peroneal nerve test to diagnose critical illness polyneuropathy and myopathy in the intensive care unit: the multicentre Italian CRIMYNE-2 diagnostic accuracy study. F1000Research. 2014;3:127.

14. Schweickert WD, Pohlman MC, Pohlman AS, Nigos C, Pawlik AJ, Esbrook CL, et al. Early physical and occupational therapy in mechanically ventilated, critically ill patients: a randomised controlled trial. Lancet. 2009;373:1874-82.

15. Hermans G, Wilmer A, Meersseman W, Milants I, Wouters PJ, Bobbaers H, et al. Impact of intensive insulin therapy on neuromuscular complications and ventilator dependency in the medical intensive care unit. Am J Respir Crit Care Med. 2007;175:480-9.
16. Sharshar T, Bastuji-Garin S, Stevens RD, Durand M-C, Malissin I, Rodriguez P, et al. Presence and severity of intensive care unit-acquired paresis at time of awakening are associated with increased intensive care unit and hospital mortality. Crit Care Med. 2009;37(12):3047-53.

17. Hermans G, Van Mechelen H, Bruyninckx F, Vanhullebusch T, Clerckx B, Meersseman $P$, et al. Predictive value for weakness and 1-year mortality of screening electrophysiology tests in the ICU. Intensive Care Med. 2015;41: 2138-48.

18. Hough CL, Lieu BK, Caldwell ES. Manual muscle strength testing of critically ill patients: feasibility and interobserver agreement. Crit Care. 2011;15:R43.

19. Kelmenson DA, Quan D, Nordon-Craft A, Malone D, Schenkman M, Moss M. Electrophysiological abnormalities can differentiate pre-hospital discharge functional status in critically ill patients with normal strength. Intensive Care Med. 2016;42(9):1504-5.

20. Mourtzakis M, Wischmeyer P. Bedside ultrasound measurement of skeletal muscle. Curr Opin Clin Nutr Metab Care. 2014;17(5):389-95.

21. Gruther W, Benesch T, Zorn C, Paternostro-Sluga T, Quittan M, Fialka-Moser $\mathrm{V}$, et al. Muscle wasting in intensive care patients: ultrasound observation of the M. quadriceps femoris muscle layer. J Rehabil Med. 2008:40:185-9.

22. Bunnell A, Ney J, Gellhorn A, Hough CL. Quantitative neuromuscular ultrasound in intensive care unit-acquired weakness: a systematic review. Muscle Nerve. 2015;52:701-8.

23. Parry SM, El-Ansary D, Cartwright MS, Sarwal A, Berney S, Koopman R, et al. Ultrasonography in the intensive care setting can be used to detect changes in the quality and quantity of muscle and is related to muscle strength and function. J Crit Care. 2015;30:e9-14.

24. Connolly B, MacBean V, Crowley C, Lunt A, Moxham J, Rafferty GF, et al. Ultrasound for the assessment of peripheral skeletal muscle architecture in critical illness: a systematic review. Crit Care Med. 2015;43:897-905.

25. Tillquist M, Kutsogiannis DJ, Wischmeyer PE, Kummerlen C, Leung R, Stollery D, et al. Bedside ultrasound is a practical and reliable measurement tool for assessing quadriceps muscle layer thickness. J Parenter Enteral Nutr. 2014;38(7): 886-90.

26. Baldwin CE, Paratz JD, Bersten AD. Diaphragm and peripheral muscle thickness on ultrasound: intra-rater reliability and variability of a methodology using non-standard recumbent positions. Respirology. 2011; 16:1136-43

27. Reid CL, Campbell IT, Little RA. Muscle wasting and energy balance in critical illness. Clin Nutr. 2004;23:273-80.

28. Sarwal A, Parry SM, Berry MJ, Hsu F-C, Lewis MT, Justus NW, et al. Interobserver reliability of quantitative muscle sonographic analysis in the critically ill population. J Ultrasound Med. 2015;34:1191-200.

29. Grimm A, Teschner U, Porzelius C, Ludewig K, Zielske J, Witte OW, et al. Muscle ultrasound for early assessment of critical illness neuromyopathy in severe sepsis. Crit Care. 2013;17:R227.

30. Campbell IT, Watt T, Withers D, England R, Sukumar S, Keegan MA, et al. Muscle thickness, measured with ultrasound, may be an indicator of lean tissue wasting in multiple organ failure in the presence of edema. Am J Clin Nutr. 1995;62:533-9.

31. Puthucheary ZA, Rawal J, McPhail M, Connolly B, Ratnayake G, Chan P, et al. Acute skeletal muscle wasting in critical illness. JAMA. 2013;310:1591-600.

32. Puthucheary ZA, Phadke R, Rawal J, McPhail MJW, Sidhu PS, Rowlerson A, et al. Qualitative ultrasound in acute critical illness muscle wasting. Crit Care Med. 2015;43:1603-11.

33. Heckmatt JZ, Leeman S, Dubowitz V. Ultrasound imaging in the diagnosis of muscle disease. J Pediatr. 1982;101:656-60.

34. Silva PE, Maldaner V, Vieira L, de Carvalho KL, Gomes H, Melo P, et al. Neuromuscular electrophysiological disorders and muscle atrophy in mechanically-ventilated traumatic brain injury patients: new insights from a prospective observational study. J Crit Care. 2018;44:87-94.

35. Kimura J. Electrodiagnosis in diseases of nerve and muscle: principles and practice. 4th ed. New York: Oxford University Press; 2013.

36. Chaudhry V, Cornblath DR, Mellits ED, Avila O, Freimer ML, Glass JD, et al. Inter- and intra-examiner reliability of nerve conduction measurements in normal subjects. Ann Neurol. 1991;30(6):841-3.

37. Bossuyt PM, Reitsma JB, Bruns DE, Gatsonis CA, Glasziou PP, Irwig L, et al. STARD 2015: an updated list of essential items for reporting diagnostic accuracy studies. BMJ. 2015;351:h5527.

38. Buderer NM. Statistical methodology: I. Incorporating the prevalence of disease into the sample size calculation for sensitivity and specificity. Acad Emerg Med. 1996;3(9):895-900. 
39. Rudis MI, Guslits BJ, Peterson EL, Hathaway SJ, Angus E, Beis S, et al. Economic impact of prolonged motor weakness complicating neuromuscular blockade in the intensive care unit. Crit Care Med. 1996;24: $1749-56$.

40. Kelmenson DA, Held N, Allen RR, Quan D, Burnham EL, Clark BJ, et al. Outcomes of ICU patients with a discharge diagnosis of critical illness polyneuromyopathy: a propensity-matched analysis. Crit Care Med. 2017; 45(12):2055-60.

41. Hermans G, Van Mechelen H, Clerckx B, Vanhullebusch T, Mesotten D, Wilmer A, et al. Acute outcomes and 1-year mortality of intensive care unitacquired weakness. A cohort study and propensity-matched analysis. Am J Respir Crit Care Med. 2014;190(4):410-20.

42. Garnacho-Montero J, Amaya-Villar R, García-Garmendía JL, Madrazo-Osuna J, Ortiz-Leyba C. Effect of critical illness polyneuropathy on the withdrawal from mechanical ventilation and the length of stay in septic patients. Crit Care Med. 2005;33:349-54.

43. Herridge MS, Tansey CM, Matté A, Tomlinson G, Diaz-Granados N, Cooper A, et al. Functional disability 5 years after acute respiratory distress syndrome. N Engl J Med. 2011;364:1293-304.

44. Sakr Y, Rubatto Birri PN, Kotfis K, Nanchal R, Shah B, Kluge S, et al. Higher fluid balance increases the risk of death from sepsis: results from a large international audit. Crit Care Med. 2017:45(3):386-94.

Ready to submit your research? Choose BMC and benefit from:

- fast, convenient online submission

- thorough peer review by experienced researchers in your field

- rapid publication on acceptance

- support for research data, including large and complex data types

- gold Open Access which fosters wider collaboration and increased citations

- maximum visibility for your research: over $100 \mathrm{M}$ website views per year

At $\mathrm{BMC}$, research is always in progress.

Learn more biomedcentral.com/submissions 